Article

\title{
The Brennan-Lomasky Test of Expressive Voting: When Impressive Probability Differences Are Meaningless
}

\author{
J. R. Clark ${ }^{1, *}$ and Dwight R. Lee ${ }^{2}$ \\ 1 Probasco Distinguished Chair, The University of Tennessee at Chattanooga, Chattanooga, TN 37403, USA \\ 2 O’Neil Center, Southern Methodist University, Dallas, TX 75275, USA; dwightl@uga.edu \\ * Correspondence: probasco@utc.edu; Tel.: +1-423-425-4118
}

Received: 27 July 2018; Accepted: 13 September 2018; Published: 19 September 2018

\begin{abstract}
We consider a test of expressive voting developed by Brennan and Lomasky (1993). They point out that in presidential elections the probability of a tie, and casting a decisive vote, increases "multi-billionfold" as the election becomes increasingly close. They conjecture that if voters are instrumentally motivated there would be enormous increases in voter turnout for presidential elections as they became close. When they find no consistent relationship between closeness and turnout in presidential elections since 1940, they conclude their test justifies a "decisive rejection of the instrumental voter hypothesis." As dramatic as such a "multi-billionfold" increase is, we argue it would not motivate voting if an instrumental payoff was the only motivation for doing so. The Brennan-Lomasky test does give the correct result, but not for the reason they emphasize. They do see reasons why voting turnout would be moderated other than the dramatic probability of a decisive vote in close elections. Furthermore, they close their test by indicating that one reason turnout might be higher in close elections is that they are more interesting, which is congenial to an expressive account. We agree. We also argue that the observed tendency for voters to confirm their biases rather than change their minds provides additional support for expressive voting.
\end{abstract}

Keywords: expressive voting; instrumental voting; voter turnout; rational voter apathy; rational ignorance; confirmation bias

JEL Classification: D70; D72; H00

\section{Introduction}

Models based on expressive voting have yielded interesting results, implying support for such things as charitable policies by uncharitable voters (Tullock 1971) and brutal policies by decent voters (Lee and Murphy 2017). This represents a range of voter support difficult to imagine if voters were motivated solely by instrumental considerations, but intuitively plausible if voters are motivated by expressive considerations. The implications of expressive voting models not only are interesting, but also are consistent with common voting behavior that is both heartening and troubling. Yet, attempts to test whether voting decisions are influenced primarily by expressive motivations under conditions (very low probability of a tied election) which imply that those motivations would dominate instrumental motivations have been less than convincing.

The most popular approach for testing the explanatory power of expressive voting has been based on evidence provided by laboratory experiments. A paper by Tyran and Wagner (2016) indicates that the evidence favoring expressive voting is mixed. Of the nine papers they examine, two support the expressive voting theory, three provide weak support, and four provide no support at 
all. Tyran and Wagner (2016, p. 15) see the mixed findings to be "found in limitations of the experiment paradigms and techniques that have been used to identify expressive voting."

We believe that stronger support exists for expressive motivations being the overwhelming, indeed sole, impetus for going to the polls in which many millions are expected to turnout. That support can be highlighted by a critical examination of a test of expressive voting put forth by Brennan and Lomasky (1993, pp. 117-20) in their widely cited book. Their test is based on the logic of expressive voting coupled with observations on the connection between the closeness of U.S. presidential elections and voter turnout. Based on that test, Brennan and Lomasky reject the instrumental voter hypothesis. Our examination of their test leads us to conclude that it always yields the correct conclusion even though the central rationale for the test is flawed.

\section{An Impressive but Meaningless Difference}

Brennan and Lomasky (1993, pp. 117-20) test of the expressive voter model is grounded in an unquestionable mathematical result that leads to a testable conjecture. The unquestionable mathematical result is that the probability of a tied election rises dramatically ("multi-billionfold") as it becomes increasingly close. That result obviously implies that the instrumental payoff to voting increases by the same "multi-billion fold" amount as the election becomes increasingly close. Their conjecture is that "[i]f voting is solely instrumental, then one would expect enormous changes in turnout with quite small changes in expected closeness" (p. 118; emphasis in original). The conjecture is easily tested with evidence from presidential elections, and clearly found to be incorrect. ${ }^{1}$ Thus, they state: "In our view, the fact that increases in expected closeness do not have a spectacular positive effect on voter turnout comes as close as one can in this muddy life to a decisive rejection of the instrumental voter hypothesis." ${ }^{2}$ (p. 119)

Interestingly, Brennan and Lomasky did not expect enormous changes in turnout. Leading up to and after discussing their test, they point to other reasons why large turnout increases should not be expected in very close elections. For example, only those prospective voters "on the margin of participation" (p. 118) would be affected by an increase in the probability of a tied election. Yet they continue to emphasize that "even if the expected difference is one-tenth of the actual一the probability of being decisive in the close election would have been many billions of times greater than in the non-close ones, and the expected corresponding benefit correspondingly so" (pp. 119-20). We find their emphasis on the startling increase in the probability of a tie as elections become close to be a misleading distraction to their case for expressive voting despite the accuracy of the math.

The problem with the Brennan and Lomasky emphasis on the multi-billionfold increase in the instrumental payoff is that such an increase would create, at most, a miniscule incentive for an instrumentally motivated potential voter to become an actual voter. Before explaining why, it helps to consider the approximate sizes of the probabilities being discussed, assuming an election with 100 million voters, roughly the turnouts of recent U.S. presidential elections. Let $\mathrm{P}_{\mathrm{T}}$ be the probability of a tied election by assuming that every voter is equally likely to vote for either one of two candidates.

1 We follow Brennan and Lomasky in assuming a presidential election with 100 million and one voters casting a vote for one of two candidates with the winner winning by one vote. So, the probability of a decisive vote (really 50 million and one decisive votes) is equal to the probability of a tied vote without one of the votes for the winner. Obviously, this ignores the complications created by the electoral college which creates the possibility of a higher probability of decisive votes being cast by one-half plus one of the voters in a small state in which the election is known to be extremely close and turns to be a swing state. This higher probability would have to be multiplied by the probability of the small state have more electoral college votes than the difference in those votes from the other states. Of course, a very large state, such as California is likely to be a swing state, but it is extremely unlikely that its presidential votes are decided by one vote. We would like to thank an unknown referee for mentioning the electoral college complication.

2 Brennan and Lomasky follow this comment by stating "[n]or does one need 'elaborate statistical technique" to make this point"' (p. 119). We agree that "elaborate statistical technique" is not needed since, as we are about to argue, potential voters motivated by instrumental interests would remain nonvoters in a presidential election no matter how close it is expected to be. 
And let $\mathrm{P}_{\mathrm{C}}$ be the probability of a tied election when every voter is slightly more likely to vote for the favored candidate than for the other candidate. In that case $\mathrm{P}_{\mathrm{T}}$ is closely approximated by 0.00008 percent, or 8 one hundred thousandths of one percent. To approximate the value of $P_{C}$, we assume that each voter votes for the favored candidate with a probability of $51 \%$, which means $\mathrm{P}_{\mathrm{C}}$ effectively is $1 / \infty$, or $0 .{ }^{3}$

The relative difference in these two probabilities, and in the instrumental payoffs in the two elections just described, are clearly as dramatic as Brennan and Lomasky claim, with the ratio $\mathrm{P}_{\mathrm{T}} / \mathrm{P}_{\mathrm{C}}$ being effectively infinite. But dramatic relative differences can be completely irrelevant to practical decision making. ${ }^{4}$ A more salient way to look at the differences in the two probabilities is as the ratio of the probabilities that an individual vote will be indecisive in the two elections just considered, or $\left(1-\mathrm{P}_{\mathrm{T}}\right) /\left(1-\mathrm{P}_{\mathrm{C}}\right)$. The ratio of these probabilities is $(1-0.00008) / 1$, or 0.99992 . As practical advice to a voter, rationally ignorant or otherwise, it would be more helpful to say that the probability of casting an indecisive vote is effectively 1 in both of the presidential elections than to say that the probability of casting a decisive vote is many billions of times greater in the former than in the latter election.

As far as the effect of the probability differences on the turnout of instrumental voters, the same advice - "it doesn't make any difference" - is still sound. Certainly, no instrumentally motivated voter who is not voting when the probability of casting a decisive vote is $1 / \infty$ is going to rush to the polls to take advantage of a marginal increase in the probability of casting a decisive vote, even if the marginal increase is multi-billions of times larger than the probability $1 / \infty$. This suggests that when Brennan and Lomasky tell us that only those "on the margin of participation" (p. 118) would be affected by the increase in the expected probability of a tied election, they are effectively referring to all would-be instrumentally motivated voters, since none of them will be voting before the expected closeness occurs, not just the few they lead us to believe they are talking about. And those voters will still be marginal, or inactive, instrumental voters after the multi-billionfold increase in the probability of a tie.

But wait. If you still have doubts about the instrumental impotence of the multi-billionfold probability increase from $\mathrm{P}_{\mathrm{C}}$ to $\mathrm{P}_{\mathrm{T}}$, there is more. Even though Brennan and Lomasky concentrate on the influence of changing probabilities of tied elections, they do mention the costs of voting, which include things like the opportunity costs of registering to vote, going to polls, waiting in line and possibly, though unlikely, giving serious thought to the candidates and their policy positions. They do point out that these costs have more negative influence on voter turnout than the positive influence of dramatic relative increases in the probability of a tied election, at least in part because those costs affect the decisions of both instrumental and expressive voters. But they do not include them in their test. Yet, voting costs make it even more obvious that the dramatic increases in the probability of a tied election Brennan and Lomasky are considering are highly unlikely to turn dormant instrumental voters into active instrumental voters. For example, assume that the opportunity cost of voting in a presidential election is $\$ 20$, a modest amount given that high-opportunity-cost people are more likely to vote than low-opportunity-cost people. If instrumental voters are aware that the probability of a tie has increased to 0.00008 , then it would require an instrumental payoff of $\$ 250,000$ from casting a decisive vote to expect to cover the cost of voting. Even if a voter overestimated the probability of casting a decisive vote by a factor of 100 , it would require an instrumental payoff of $\$ 2500$ from casting

3 The probabilities of a tied election with 100 million voters are derived from Brennan and Lomasky (1993, p. 57, Table 4.1). The table gives several differences in the probability that each voter will vote for one of two candidates or policies, with the first being 0 , meaning a 0.5 probability for each, and the last being 0.01 , meaning a 0.51 probability for the favorite and a 0.49 probability for the other. The column below each probability is the dollar payoff from casting a decisive vote that would be required to give the voter an expected return of one dollar, given the number of voters shown in the far-left hand column. Those numbers go from 101 to 100 million. We made use of the 0 and 0.01 columns and the 100 million voters row. At the 100 million, 0 coordinate is 12,500 which implies the probability of a tied election is $1 /(12,500)$ or 0.00008 . For the 100 million, 0.01 coordinate is $\infty$, which implies a probability of a tied election of effectively 0 .

4 Consider space travel. The MACSO647-JD galaxy is about 13.3 billion light years from earth, but the instrumental payoff from sending a space probe there is indistinguishable from sending one to the Andromeda X1 galaxy, which is only 2.4 million light years from earth. 
a decisive vote to cover the cost of voting. ${ }^{5}$ On the other hand, it is easy to imagine an expressive voter receiving, with a probability of 1 , enough expressive satisfaction from voting to comfortably exceed the $\$ 20$ cost of voting.

Again, we see Brennan and Lomasky's focus on the effect of close elections on probabilities of tied elections as a misleading distraction in their case for expressive voting. In other words, the effect of large relative increases in miniscule probabilities of a tied election on voter turnout is miniscule.

We believe that if there is a tendency for increased voter turnout when elections are close, it is the result of expressive voters responding to the additional attention close elections receive, not of instrumental voters responding to the dramatic increases in the probability of a tied vote as elections become close. Brennan and Lomasky's test will always be correct by seeing small increase, or no increases at all, as justifying the rejection of the instrumental voter hypothesis, but for the wrong reason.

It is not even clear that Brennan and Lomasky will disagree with our criticism. As they say in concluding the discussion of their test:

Close contests in the sporting arena are more engaging and induce more spectator interest than clear-cut contests. Given the analogy between voter and spectator behavior, it would surely not be implausible if closer contests induced more involvement in the electoral setting as well. In that sense, some small connection between closeness and turnout of the kind that empirical work seems to reveal (or at least does not reject) is quite congenial to the expressive account. (p. 120)

\section{Conclusions}

The concepts of rational voter apathy, rational voter ignorance and expressive voting are all based on the small probability that an individual's vote will be decisive, at least in large-participation elections. As far as we know, there has been little controversy about the influence of instrumental or expressive motivations of voters on the validity of rational voter apathy or ignorance.

Downs (1957, p. 48) clearly assumes instrumental voting when stating that "[a] rational voter first decides what party will benefit him the most ... [but] even if he prefers party $A$, he is wasting his vote on $\mathrm{A}$, if it has no chance of winning ... the relevant choice in this case is between B and C. Since a vote for $\mathrm{A}$ is not useful in the actual process of selection, casting it is irrational." There is no indication of an expressive benefit here. ${ }^{6}$ When considering voter apathy, or abstaining (p. 265) Downs points out that "voting is inherently costly ... [and] since the returns to voting are often miniscule, even low voting cost may cause many partisan citizens to abstain." In considering rational apathy, or what they call "rational abstention," Brennan and Lomasky (1993, pp. 65-66) see "[t]he general thrust of the public choice literature on the turnout issue is to argue that the probability of being decisive is nothing like large enough to explain turnouts that are observed without appealing to something other than instrumental returns." (p. 66). They then consider Nash equilibrium models that attempt to show how "substantial voter turnout may occur in a totally instrumental, outcome-oriented polity" (p. 66). While Brennan and Lomasky "do not deny that some equilibria of this kind may exist in some cases-[they] believe the prospect unlikely. What [they] do deny is that the resulting equilibria much

5 People commonly respond to the argument that a vote is unlikely to make any difference in the outcome of an election by pointing to close elections, such as the Florida presidential election in 2000. But the final official count had a 537-vote difference between Bush and Gore. So, one more vote for Bush would have made no difference. But this does not mean that people cannot convince themselves that their vote is far more likely to be decisive than it is. Findings by Kahneman and Tversky, and reported in Kahneman (2011, p. 315-16), indicate that voters tend to respond to probabilities less than 1 as if they are zero. Yet, if a highly improbably event becomes the focus of attention, like a terrorist attack, the probability of it occurring can be perceived as far greater than it is. Whether this means that some people really believe their vote in a presidential election is likely to be decisive seems to us to be pushing rational voter ignorance a little too far.

6 Downs (1957, p. 46) does say "[t]hat to decide what impact each government act has upon his [the voter's] income, he appraises it as good or bad in light of his own view of 'the good society'." And it appears he is referring here to "hypothetical streams of utility income." Yet this "income" does not seem to help offset the cost of voting when deciding to vote or not to vote in Down's discussion. 
resemble those we observe in electoral practice" (p. 69). What all this seems to say in a qualified way is that expressive voting is the most reasonable explanation for why voting turnouts in large-participation elections are anywhere near as high as they are.

The empirical evidence is overwhelming that a large percentage of voters in large-participation elections lack such basic information on the political process as who their political representatives are, the position of those representatives on important issues, or the pros and cons of the different positions. ${ }^{7}$ None of this evidence on rational voter ignorance depends on whether voters are motivated by instrumental or expressive interests. One might argue, along the lines of Brennan and Lomasky, that if the dominant reason for voting is instrumental then a dramatic increase in the probability of a tied election, and therefore of a decisive vote, would not only motivate an increase in voter turnout, but also the average voter's being more informed politically to better evaluate the relative instrumental payoffs from alternative voting decisions. We know of no attempt to use this logic, along with possible reductions in voter ignorance as elections got close, to conduct a test of the instrumental voter hypothesis. There are two reasons why we would not expect such a test to be attempted. First, as we have argued in this paper, even the most dramatic increase in the probability of a tie in the large-participation elections being considered would have little, if any, effect on either voter turnout of instrumental voters, or on their desire to become more informed politically. Second, it is much easier to measure changes in voter turnout than to measure how the political ignorance of the average voter changes as the probability of tied elections increases.

Interestingly, if instrumental voters exist and could be identified, we would expect them to be more informed politically on average than voters motivated solely by expressive satisfaction for a reason having nothing to do with the probability of tied elections. The return received by an expressive voter depends entirely on how good he feels about voting for something or someone he believes to be worthy of the support of decent people like himself, such as those he identifies with as friends, associates, and role models. Such beliefs might result from serious study of complicated issues, but often they develop from the tendency to be in agreement with the views that prevail in one's social group, agreement which serves one's interest in becoming or remaining an accepted member of that group. The satisfaction one gets from such beliefs as a voter and a member of a like-minded group depends far more on retaining the prevailing beliefs of one's ideological tribe than it does on their accuracy. ${ }^{8}$ So, once an expressive voter has developed a political ideology that allows him to acquire a sense of moral virtue at little personal cost at the polls, and to enjoy the political comradery of his ideological fellow travelers, he has little motivation to seek out information that might call his political beliefs into question. Of course, arguments hostile to one's political beliefs cannot be completely avoided, but they can be, and typically are, easily neutralized with confirmation bias. If most voters voted instrumentally because they believed their vote was likely to be decisive, they would be more open to arguments indicating that their political beliefs are mistaken. The fact that confirmation bias is recognized as a strong influence on voting decisions is further evidence that voting is primarily motivated by expressive instead of instrumental interests. ${ }^{9}$

This short paper should not be thought of as a criticism of Brennan and Lomasky's impressive book, Democracy $\mathcal{E}$ Decision. It is the seminal work on expressive voting, containing 225 pages of insights on the theory and applications of one of the key contributions of public choice to voting. Our paper considers only four of those pages to argue that the dramatic increase in the probability of a tie in a large-participation election is far less important to their rejection of the instrumental voter hypothesis than they seem to indicate. We believe that our argument adds insight into the theory of expressive voting and that Brennan and Lomasky will agree. We hope so.

\footnotetext{
See Somin (2016, chp. 1).

See Mason (2018). The entire book is relevant to this discussion, but particularly Chapter 1 .

See Nickerson (2016).
} 
Author Contributions: J.R.C. and D.R.L. collaborated on previous published research in expressive voting from which this application of the Brennan-Lomasky Test grows. D.R.L. wrote preliminary draft of the current article while J.R.C. edited drafts, submitted the article for review, and proofed final copy.

Funding: This research received no external funding.

Conflicts of Interest: The authors declare no conflict of interest.

\section{References}

Brennan, Geoffrey, and Loren Lomasky. 1993. Democracy E Decision: The Pure Theory of Electoral Preference. Cambridge: Cambridge University Press.

Downs, Anthony. 1957. An Economic Theory of Democracy. New York: Harper and Row.

Kahneman, Daniel. 2011. Thinking, Fast and Slow. New York: Farrar, Straus and Giroux.

Lee, Dwight R., and Ryan H. Murphy. 2017. An expressive voting model of anger, hatred, harm and shame. Public Choice 173: 307-23. [CrossRef]

Mason, Lilliana. 2018. Uncivil Agreement: How Politics Becomes Our Identity. Chicago: The University of Chicago Press.

Nickerson, Ray. 2016. Confirmation bias: A psychological phenomenon that helps explain why pundits got it wrong. The Conversation. November 21. Available online: http://theconversation.com/confirmationbias-a-psychological-phenomenon-that-helps-explain-why-pundits-got-it-wrong-68781 (accessed on 17 September 2018).

Somin, Ilya. 2016. Democracy and Political Ignorance: Why Smaller Government Is Smarter. Stanford: Stanford University Press.

Tullock, Gordon. 1971. The charity of the uncharitable. Western Economic Journal 9: 379-92.

Tyran, Jean-Robert, and Alexander K. Wagner. 2016. Experimental evidence on expressive Voting. In The Oxford Handbook of Public Choice. Edited by Roger D. Congleton, Bernard N. Grofman and Stefan Voigt. Oxford: Oxford University Press, Available online: https://papers.ssrn.com/sol3/papers.cfm?abstract_id= 2867954 (accessed on 17 September 2018).

(C) 2018 by the authors. Licensee MDPI, Basel, Switzerland. This article is an open access article distributed under the terms and conditions of the Creative Commons Attribution (CC BY) license (http:/ / creativecommons.org/licenses/by/4.0/). 